\title{
Recontar para ressignificar: passado e presente em pauta no racismo estrutural
}

Retelling to Ressignify: Past and Present at the Agenda on Structural Racism

Priscila Nottingham de Lima*

ALMEIDA, Silvio Luiz de. Racismo estrutural. São Paulo: Sueli Carneiro; Editora Jandaíra: 2020.

Silvio Luiz de Almeida, autor da obra em questão, é brasileiro, nascido em 1977, natural da cidade de São Paulo. Possui o título de doutor em Direito pelo Departamento de Filosofia e Teoria Geral do Direito da Universidade de São Paulo, além de graduações nas áreas do Direito e da Filosofia. Atua principalmente como professor universitário em algumas instituições no Brasil e desenvolve estudos interdisciplinares que abrangem, dentre outras categorias, o escopo do racismo e as suas raízes histórico-estruturais.

Na pesquisa publicada sob o título de Racismo estrutural, Almeida apresenta, de modo criativo e inovador, o racismo não apenas como uma manifestação concernente à esfera individual e institucional, mas especialmente a partir de complexas relações de poder que se reinventam num macroprocesso histórico e sistêmico, capaz de se manter hegemônico na organização política e econômica da sociedade contemporânea. As consequências desse movimento refratam em desigualdades e violências hodiernas que, apesar dos avanços legais e democráticos, continuam a hierarquizar a humanidade a partir da racialização. Conforme reforça o intelectual, "Pessoas racializadas são formadas por condições estruturais e institucionais." (Almeida, 2020, p. 64).

Para demarcar esse racismo estrutural, o intelectual questiona as concepções construídas por interpretações equivocadas desse racismo, por vezes percebido como um fenômeno de orientação individual ou institucional. Essa classificação, dada por Almeida, tem por objetivo esclarecer o leitor, de modo didático, sobre as nuances e limitações dessas percepções e sobre a importân-

\footnotetext{
* Universidade Estadual do Ceará (UECE), Fortaleza, CE, Brasil. priscilanotty@gmail.com <https:// orcid.org/0000-0003-4591-1265>
} 
cia de saber interpretá-las para que a realidade concreta possa ser desvendada. Almeida chama atenção para o fato de que, geralmente, a literatura recorrente que trata desse tema aborda o racismo institucional e estrutural como sinônimos. Todavia, apesar de serem categorias centrais, ele considera que se reportam a fenômenos sociológicos diferenciados (Almeida, 2020, p. 36).

Para esmiuçar o exposto, Almeida apresenta em tópicos, ao final do primeiro capítulo, esses conceitos. Na concepção individualista, o estudioso explica que o racismo é percebido a partir de aspectos éticos ou psicológicos, que se refratam na sociedade a partir da discriminação cotidiana. Segundo essa interpretação, seria possível se dar conta do enfrentamento da violência através da reeducação da população e da aplicação de leis repressoras àqueles que promovem práticas discriminatórias diretas. Contudo, apesar de reconhecer a importância dessas iniciativas, Almeida reforça que "[...] não podemos deixar de apontar o fato de que a concepção individualista [...] tem sido a base de análises sobre o racismo absolutamente carentes de história e de reflexão sobre seus efeitos concretos." (Almeida, 2020, p. 37).

Em relação à concepção institucional, o autor situa a importância dos avanços que ela trouxe ao superar a ideia limitada do racismo como uma irracionalidade que demarcaria uma atitude protagonizada pelos excessos de sujeitos ou coletivos eticamente ou psicologicamente corrompidos. O debate institucional incorpora uma visão mais ampliada que envolve o funcionamento das instituições como questão central. Para compreender essa abordagem, é fundamental situar o significado das instituições em si. Nessa concepção, a problemática poderia ser confrontada através de uma recondução de ações e subjetividades políticas e de alcance socioeconômico que fossem dotadas de caráter inclusivo e reparador. As instituições seriam, então, “[...] a materialização das determinações formais da vida social [...]” (Almeida, 2020, p. 39).

A concepção estrutural, por sua vez, consegue vislumbrar que as instituições refletem aquilo que a sociedade assimilou como ordem social. Dessa maneira, reconduzir as ações e as posturas institucionais é importante, mas não é suficiente para o enfrentamento do racismo. Nessa interpretação, o racismo passa a ser percebido a partir de suas raízes históricas, possuindo uma dimensão política, com consequências que desencadeiam uma sistemática que discrimina os grupos racializados. Essa compreensão é importante para aprofundar o debate do racismo e para se repensarem estratégias de resistência com alcance mais profundo, assertivo e duradouro. Para desmantelar essa estrutura, há de se compreender a sua extensão, origem e múltiplas dimensões.

Isto posto, faz-se importante apresentar um panorama geral da organiza- 
ção do livro. O material está disposto em cinco capítulos abrangentes, na seguinte ordem: raça e racismo; racismo e ideologia; racismo e política; racismo e direito; racismo e economia. Cada um desses temas está subdividido em diversos subtópicos, sendo o primeiro deles intitulado "A raça na história", situando o colonialismo como um projeto de orientação eurocentrada, com aspirações expansionistas e predatórias; marco nascedouro da classificação dos diferentes grupos humanos numa perspectiva de racialização hierarquizada. Nessa construção, originada em meados do século XVI, o europeu paulatinamente torna-se a referência de ser humano universal, sendo todos os outros povos considerados versões menos evoluídas.

$\mathrm{Na}$ sequência de seu argumento, Almeida sinaliza, no projeto iluminista do século XVIII, um recrudescimento desse transcurso, pois surgem “[...] ferramentas que tornariam possível a comparação e, posteriormente, a classificação, dos mais diferentes grupos humanos com base nas características físicas e culturais." (Almeida, 2020, p. 26). À vista disso, esse ideário iluminista de orientação liberal apresenta uma aparente contradição: ao mesmo tempo em que reivindica direitos de liberdade e democracia contra a nobreza feudal, nega o estatuto de humanidade a todos os indivíduos que estão fora de pré-requisitos bastante delimitados: homem, branco, ocidental e europeu. $\mathrm{O}$ autor insere nesse debate o marco da Revolução Haitiana em 1791, na qual a população reivindicou a extensão das conquistas de direitos da Revolução Francesa àquela nação. Todavia, "Com a Revolução Haitiana, tornou-se evidente que o projeto liberal-iluminista não tornava todos os homens iguais e sequer faria com que todos os indivíduos fossem reconhecidos como seres humanos." (Almeida, 2020, p. 27).

Acrescido ao discurso filosófico-liberal, somam-se ainda, a partir do século XIX, as iniciativas de orientação biológica, constituindo o que Almeida vai intitular de racismo científico, o qual “[...] obteve enorme repercussão e prestígio nos meios acadêmicos e políticos do século XIX, como demonstram, além das obras de Arthur Gobineau, as obras de Cesare Lombroso, Enrico Ferrari e, no Brasil, Silvio Romero e Raimundo Nina Rodrigues." (Almeida, 2020, p. 29). Schwarcz (2019) se refere a esse segmento como "darwinismo racial", que buscava legitimar a desigualdade socioestrutural orquestrada pela branquitude a partir de uma suposta diferença genético-biológica, segundo a qual os brancos euro-ocidentais estariam no topo da "civilidade" e da evolução, sendo, portanto, os mais indicados para determinar normativas e parâmetros com vistas a "contribuir" com os avanços civilizatórios dos demais.

As críticas a essas abordagens emergem no Brasil apenas no século XX, 
contestando a existência de determinações biológicas capazes de classificar ou hierarquizar a humanidade, independentemente de moral, cultura, religião ou qualquer outro traço de diversidade. Ainda assim, Almeida chama a atenção para outra estratégia que representa severos rebatimentos racistas: a ascensão da ideia de democracia racial. Inaugurada em 1930 e disseminada especialmente a partir da obra de Gilberto Freyre Casa-grande \& Senzala (2006) apesar da alcunha do termo ter sido de autoria do médico alagoano Arthur Ramos -, a democracia racial “[...] consiste em afirmar a miscigenação como uma das características básicas de identidade nacional, como algo moralmente aceito em todos os níveis da sociedade, inclusive pela classe dominante." (Almeida, 2020, pp. 178-179). Essa ideologia se instala no imaginário social do país de modo contumaz e refrata seus efeitos até os dias atuais, trazendo negação do racismo e romantização de relações que, na realidade, são extremamente desiguais, violentas e excludentes.

Destarte, o enraizamento do racismo de modo institucional e sistêmico permaneceu e permanece articulando modalidades mais sofisticadas de manutenção do poder, configurando-se como um fenômeno que não pode ser compreendido apenas a partir de uma definição conceitual ou lógica, sendo necessária igualmente a compreensão de sua dimensão material, pois é inegável que "[...] a lógica da colônia materializa-se na gestão praticada pelos Estados contemporâneos, especialmente nos países da periferia do capitalismo [...]" (Almeida, 2020, p. 125). Isto posto, Almeida explica que a persistência do racismo demanda "[....] em primeiro lugar, a criação e a recriação de um imaginário social em que determinadas características biológicas ou práticas culturais sejam associadas à raça e, em segundo lugar, que a desigualdade social seja naturalmente atribuída à identidade racial dos indivíduos [...]" (Almeida, 2020, p. 74). A partir disso, a branquitude assume posição de privilégio, que passa a ser legitimada na contemporaneidade sob um suposto status de meritocracia.

As estratégias, portanto, se renovam, de modo que a retórica hegemônica sustenta, ainda no século XXI, um pretenso padrão de valores e verdades supostamente universais. Conforme reforça Wallerstein: “[...] o universalismo dos poderosos sempre foi parcial e distorcido" (Wallerstein, 2007, p. 27), e esconde-se sob o manto de palavras como "meritocracia", "direitos humanos" e "democracia”, mas visa, na verdade, assegurar a manutenção de seu lugar privilegiado. Dessa forma, forças e consensos ideológicos se orquestram no processo de dominação, que, na conjuntura do capital, ecoam numa verdadeira tecnologia do poder, uma vez que "[...] para se renovar, o capitalismo pre- 
cisa muitas vezes renovar o racismo, como, por exemplo, substituir o racismo oficial e a segregação legalizada pela indiferença diante da igualdade racial sob o manto da democracia." (Almeida, 2020, p. 184).

A partir dessa interpretação, Almeida reforça que o racismo deve ser percebido como uma questão central, não apenas como uma adjacência do conflito entre classes sociais, tão evocado em tempos de capital, visto que "[...] classe e raça são elementos sobredeterminados.” (Almeida, 2020, p. 185). Assim, para alcançar a consciência de classe é indispensável se considerar o problema racial, pois ambos estão fortemente imbricados. A divisão social do trabalho, portanto, é atravessada pelo racismo. Prova disso é a reduzida representatividade da população negra em cargos de gerência, chefia ou propriedade dos meios de produção. Ao mesmo tempo, a negritude predomina nas posições de trabalho mais precárias e inseguras.

O capitalismo emerge para substituir a violência de orientação eminentemente agrária, servil e escravocrata pela exploração do trabalho livre e assalariado, com base em suposta liberdade individual e no contrato. Nesse amálgama, o poder político assume a impessoalidade, na forma de Estado, atuante através de normativas jurídicas com vistas a regulamentar e a assegurar a ordem social. Transitando entre posicionamentos de menor ou maior intervenção na sociedade, esse Estado é uma entidade fundamental para pensar o racismo estrutural em profundidade.

No debate estabelecido sobre o surgimento histórico do Estado moderno, Almeida faz referência às estruturas estatais como legitimadoras do racismo, pois "É por meio do Estado que a classificação de pessoas e a divisão dos indivíduos em classes e grupos é realizada.” (Almeida, 2020, p. 87). Nessa interpretação, o autor assinala que, inicialmente, as teorias liberais dirigem pouca ou nenhuma atenção à pauta racial. Elas preveem o racismo como uma irracionalidade e apostam na ética e no direito para se resolver essa questão. Entretanto, como não é possível combater o racismo a partir de uma perspectiva individualista e contratualista, gestadas predominantemente no protagonismo do homem branco, essa iniciativa produz interpretações equivocadas. Assim, de acordo com Almeida: "As teorias que analisam o Estado do ponto de vista da ética se restringem a descrever aspectos institucionais ou jurídicos da organização política, ou não conseguem oferecer explicações suficientes sobre a relação entre raça e política." (Almeida, 2020, p. 90).

Desse modo, não é de se surpreender que Estados que se autoproclamam tão desenvolvidos tenham sustentado práticas extremamente racistas, como foi o caso da segregação racial norte-americana até meados da década de 1960, 
com proibições, por exemplo, relativas aos casamentos inter-raciais, ou restrições legais concernentes ao acesso à educação, aos serviços de saúde, à assistência e à moradia - serviços muito mais precários para a população afro-americana. Para Almeida, interpretar os meandros do Estado capitalista, que não é neutro, mas campo de disputa de interesses e coletividades, é uma saída possível para se vislumbrarem alternativas mais inclusivas e reparadoras à população marginalizada.

Diante do exposto, conclui-se que revisitar o passado para recontar os fatos históricos sob outros olhares, em novas perspectivas, é fundamental para a promoção da diversidade de protagonismos usurpados, pois ignorados ou marginalizados pela perspectiva eurocentrista. O racismo estrutural, portanto, se apresenta como um processo centenário que se enraíza nas relações de poder, com rebatimentos não apenas na vida cotidiana dos sujeitos racializados, mas nas práticas institucionais, políticas e econômicas, reiniciando ciclos aparentemente intermináveis de exploração, exclusão, violência e desumanização do outro.

Para se engendrarem narrativas politicamente responsáveis, além de mais assertivas e inclusivas, é indispensável se considerar essa pluralidade de perspectivas, que complementam uma realidade de natureza muito mais complexa e, por isso mesmo, mais próxima do real. Sobre a importância disso, Schwarcz salienta: "História não é bula de remédio nem produz efeitos rápidos de curta ou longa duração. Ajuda, porém, a tirar o véu do espanto e a produzir uma discussão mais crítica [...]" (Schwarcz, 2019, p. 26). Para ilustrar esse debate, vale trazer o testemunho de Ribeiro (2019) ao relatar que, na infância, aprendeu sobre a população negra apenas que ela havia sido escravizada, "[...] como se não tivesse existido uma vida anterior nas regiões de onde essas pessoas foram tiradas à força." (Ribeiro, 2019, p. 07). Para se desconstruírem mitos, faz-se necessário e urgente resgatar-se o debate do racismo estrutural.

\section{REFERÊNCIAS}

ALMEIDA, Silvio Luiz de. Racismo estrutural. São Paulo: Sueli Carneiro; Editora Jandaíra: 2020.

FREYRE, Gilberto. Casa-grande \& senzala: formação da família brasileira sob o regime da economia patriarcal. 51 Ed. São Paulo: Global, 2006.

RIBEIRO, Djamila. Pequeno manual antirracista. São Paulo: Companhia das Letras, 2019. 
SCHWARCZ, Lilia Moritz. Sobre o autoritarismo brasileiro. São Paulo: Companhia das Letras, 2019.

WALLERSTEIN, Immanuel Maurice. O universalismo europeu: a retórica do poder. Tradução de Maria Beatriz de Medina. São Paulo: Boitempo, 2007. 